\title{
Is There a Geomagnetic Component Involved with the Determination of G?
}

\author{
Michael A. Persinger, Linda S. St-Pierre \\ Laurentian University, Sudbury, Canada \\ Email: mpersinger@laurentian.ca, Ix_stpierre@laurentian.ca
}

Received 27 February 2014; revised 25 March 2014; accepted 21 April 2014

Copyright (C) 2014 by authors and Scientific Research Publishing Inc.

This work is licensed under the Creative Commons Attribution International License (CC BY). http://creativecommons.org/licenses/by/4.0/

(c) (i) Open Access

\section{Abstract}

We compared the small quantitative changes (range) in G over repeated measures (days) with recently improved methods of determinations and those recorded over 20 years ago. The range in the Newtonian constant of gravitation $G$ is usually in the order of $400 \mathrm{ppm}$ as reflected in experimentally-determined values. The moderate strength negative correlation between daily fluctuations in $G$, in the range of $3 \times 1^{-3}$ of the average value, and an index of global geomagnetic activity reported by Vladimirsky and Bruns in 1998 was also found for the daily fluctuations in the angular deflection $\theta$ (in arcseconds) and geomagnetic activity within $24 \mathrm{hr}$ for the Quinn et al. $2013 \mathrm{data}$. A temporal coupling between increases of geomagnetic activity in the order of $10^{-9} \mathrm{~T}$ with decreases in $G$ in the order of $10^{-14} \mathrm{~m}^{3 \cdot} \mathrm{kg}^{-1} \cdot \mathrm{s}^{-2}$ could suggest a recondite shared source of variance. The energy equivalence for this change in $\mathrm{G}$ and geomagnetic activity within $1 \mathrm{~L}$ of water is $\sim 3 \times 10^{-14} \mathrm{~J}$.

\section{Keywords}

Gravitational Constant Variations, Geomagnetic Activity, Energy Convergence, Electromagnetic-Gravitational Interactions

\section{Introduction}

The recent quantitative measurements by Quinn et al. [1] who employed two methods to estimate the Newtonian gravitational constant $\mathrm{G}$ were remarkably congruent. The servo and free-deflection (torsion balance) or Cavendish methods yielded values of $6.67520 \times 10^{-11} \mathrm{~m}^{3} \cdot \mathrm{kg}^{-1} \cdot \mathrm{s}^{-2}$ and $6.67566 \times 10^{-11} \mathrm{~m}^{3} \cdot \mathrm{kg}^{-1} \cdot \mathrm{s}^{-2}$, respectively. The difference in G between the two methods was $4.6 \times 10^{-15} \mathrm{~m}^{3} \cdot \mathrm{kg}^{-1} \cdot \mathrm{s}^{-2}$ or $\sim 70 \mathrm{ppm}$. The difference is within the range of $10^{-4}$ which was considered by Vladimirskii [2] to be the boundary for accuracy to infer $\mathrm{G}$ with torsion balances. Vladimirskii [2] and later Vladimirsky and Bruns [3] reported a source of variability that could account for the spread in G of $\sim 400$ ppm noted by Quinn et al. [1]. 
This source involved heliophysical perturbations as inferred by inferences of geomagnetic activity. Subtle variations in $\mathrm{G}$ which are systematically and quantitatively related to alterations in geomagnetic activity could be secondary to direct influences upon instrumentation [2] [3]. However if there is a third variable that is shared by both variation in $\mathrm{G}$ and geomagnetic activity, it may have both theoretical and practical significance. Here we indicate that two series of measurements from different localities, separated by more than two decades revealed comparable magnitudes of negative correlations between daily subtle changes in $G$ and ambient geomagnetic activity.

\section{Methods and Results}

According to Figure 3 from [1] the means of the coefficients for $\mathrm{G}$ from 11 different sources range from 6.6725 to 6.6756 or $\sim 3.1 \times 10^{-3}$ of an average for G. This value is within error measurement variability of $5.2 \times 10^{-3}$ reported [3] between days when the interplanetary magnetic field shifted from a positive to a negative sign and geomagnetic $A_{p}$ values ranged between -8 and $+8 \mathrm{nT}$. In those previous measurements [2] between 29 August and 23 December 1991, the mean value for the coefficient of $G$ was 6.6728 for the 77 measurements during which $A_{p}$ values were $<15 \mathrm{nT}$ and 6.6675 during the 48 measurements during which the $A_{p}$ values were $>30 \mathrm{nT}$.

The difference in G, $5.3 \times 10^{-3}$, is equivalent to $5.3 \times 10^{-14} \mathrm{~m}^{3} \cdot \mathrm{kg}^{-1} \cdot \mathrm{s}^{-2}$. The Pearson correlation was calculated from Vladimirsky and Bruns' data [3] between the different daily values of $G$ and the $A_{p}$ indices in their Figure 1. For those 16 days the Pearson $r$ coefficient was -0.50 (Spearman rho $=-0.53$, both, $p<0.05$ ). To ensure daily specificity, the correlations between the two values with the lag or lead days were completed; they were not significant statistically (all rs and rhos $<|0.20|$ ). Although the dispersion (Standard Error of the Estimate) was substantial with such a weak correlation, the slope indicated that for every 0.01 decrease in $G$ between 6.6840 and 6.6705, there was a $3.8 \mathrm{nT}$ increase in $\mathrm{A}_{\mathrm{p}}$ values.

For the Quinn et al. [1] data shown in Figure 2 from their paper the Pearson correlation between $\theta \mathrm{a}^{-1} \cdot \mathrm{s}^{-1}$ per day (range $=31.542$ to 31.549) and the Planetary A index (Sec) from http://www.dxlc.com/solar/indices.html (range 2 to 23) during the previous $24 \mathrm{hr}$ for the 10 days measured from 31 August to 11 September 2007 was $-0.70(\mathrm{p}<0.05)$. The Spearman rho $(-0.68, \mathrm{p}<0.05)$ was comparable indicating the effect was not due to outliers. Each of the 10 averages was based upon 34 values of angular deflection extracted from successive 30 minute (the limit where white noise dominated) data collections. Because $\mathrm{G}=\tau \Gamma^{-1}$ where $\tau=$ the measured torque and $\Gamma$ is $\left(70 \mathrm{Mmr}^{4} \cdot \mathrm{R}^{-5}\right.$ ) fixed by the method, an increase in $\theta=\tau \mathrm{c}^{-1}$ (c is the stiffness of the suspension) would imply an increase in $\mathrm{G}$.

Lag/lead correlations for each day before and after the days in which these correlations were obtained were all $<|0.20|$, that is not significant statistically, which is similar to the results found for Vladimirsky and Bruns. The coefficient for the slope for the Quinn effect indicated that for every $0.001 \theta \mathrm{a}^{-1} \cdot \mathrm{s}^{-1}$ decrease there was a 1.6 unit increase in the Planetary A index. The quantitative proportion is similar to that obtained for [3].

\section{Discussion}

The z-score differences for the correlation coefficients for the negative associations between the inferences of geomagnetic activity and G were not significant statistically for the Vladimirsky and Burns [3] and Quinn et al. [1] results. Both were negative indicating a shared source of variance between the two qualities such that as the intensities of G increase the intensities of geomagnetic background fluctuations decrease. Vladimirski [2] suggested that "magnetoplasticity" from the low to ultra-low electromagnetic fields associated with geomagnetic activity may have affected the elasticity parameters of the suspending thread of the torsion pendulums. He suggested that such variables could explain the enigma of why the upper limit of accuracy for measurements of G with torsion balances could not exceed $10^{-4}$. However a recondite quantitative equivalence between some quality of gravity and electromagnetic phenomena [4] could also be revealed.

Even a simplistic comparison of the energies associated with force suggests a shared convergence for $1 \mathrm{~L}$ $\left(10^{-3} \mathrm{~m}^{3}\right)$ of water, perhaps the most relevant proportion of mass on the earth's surface. The change of $\mathrm{G}$ of $3 \times$ $10^{-15} \mathrm{~m}^{3} \cdot \mathrm{kg}^{-1} \cdot \mathrm{s}^{-2}$ multiplied by $\left(1 \mathrm{~kg}^{2} / 0.1 \mathrm{~m}(10 \mathrm{~cm})\right)$ is $3 \times 10^{-14} \mathrm{~J}$. On the other hand the energy represented $\left(\mathrm{B}^{2} / 2 \mu\right)$ within this volume for a mean variation of $\sim 8 \mathrm{nT}$ from Vladimirsky and Burns' [3] experiments also results in a value of $\sim 3 \times 10^{-14} \mathrm{~J}$. Although there are insufficient data to conclude that they share the same source of variance at this time, the similarity of quantitative values suggests that further examination of this possible coupling is warranted. 


\section{Acknowledgements}

Thanks to Dr. Blake T. Dotta and Viger Persinger for technical contributions.

\section{References}

[1] Quinn, T., Parks, H., Speake, C. and Davis, R. (2013) Improved Determination of G Using Two Methods. Physics Review Letters, 111, 101102. http://dx.doi.org/10.1103/PhysRevLett.111.101102

[2] Vladimirskii, B.M. (1996) Measurements of the Gravitational Constant and Heliogeophysical Electromagnetic Perturbations. Biophysics, 40, 915-923.

[3] Vladimirsky, B.M. and Bruns, A.V. (1998) Influence of the Sector Structure of the Interplanetary Magnetic Field on the Results of Measurements of the Gravitational Constant. Biophysics, 43, 720-725.

[4] Persinger, M.A. (2012) Potential Origins of a Quantitative Equivalence between Gravity and Light. Open Astronomy Journal, 5, 41-43. http://dx.doi.org/10.2174/1874381101205010041 